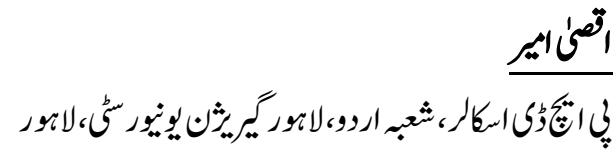

$$
\begin{aligned}
& \text { ؤكمُمحالمخان }
\end{aligned}
$$

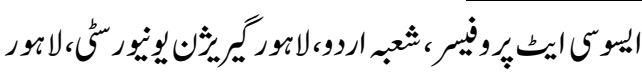

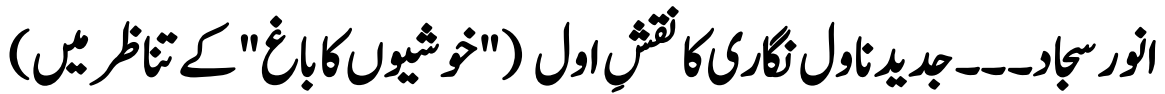

\section{Aqsa Amir}

Ph.D Scholar Department of Urdu Lahore Garrisson University Lahore.

Dr. Muhammad Alam Khan

Associate Professor, Department of Urdu, Lahore Garrison University, Lahore

\section{Anwar Sajjad... The First Image of Mmodern Novels (In the context of "Khushion Ka Bagh"}

Anwar Sajjad was renowned fiction writer in Urdu Literatue. He is considered trend setter in the Urdu short stories as well as Urdu Noval writer. In this essay, his famous noval "Khushion Ka Bagh" is being discussed in the perspective of modern fiction the traditiona modern fiction and it is elaborated that how milestone in the history of noval writing. It is also analysed the roal of Dr. Anwar Sajjad to create a new trend in the history of literature.

Key Words: Renowed, Fiction, Vrdu Literature, Trend, Short Stories.

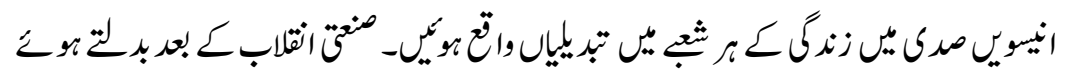

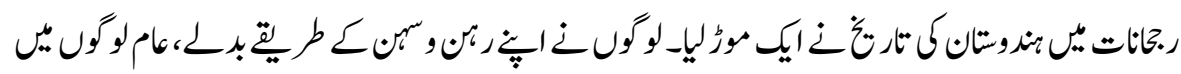

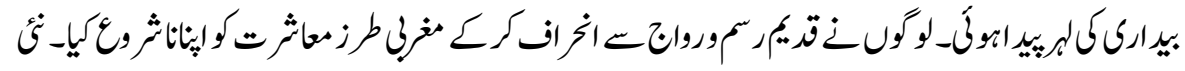

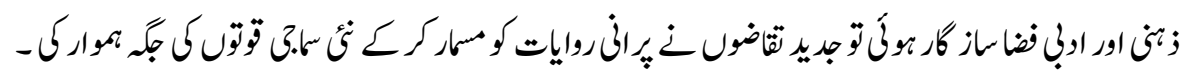

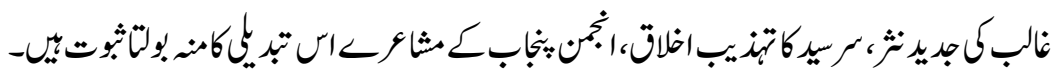




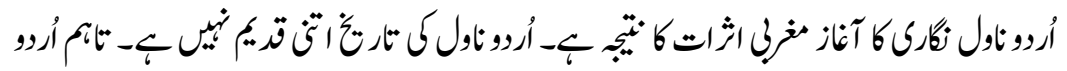

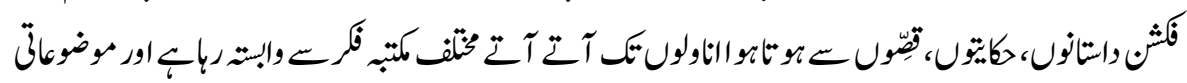

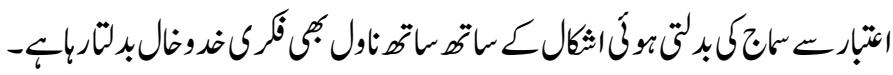

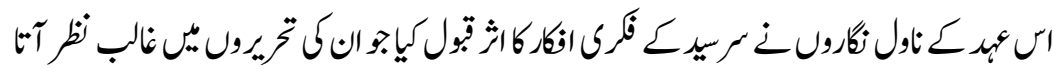

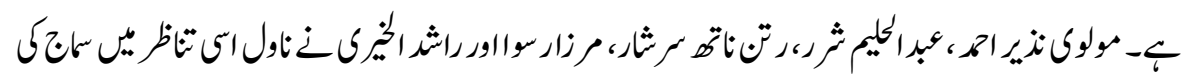

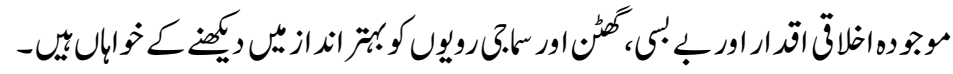

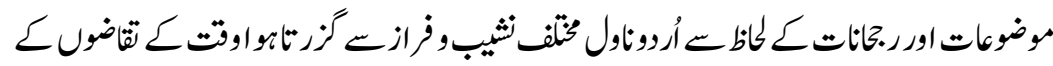

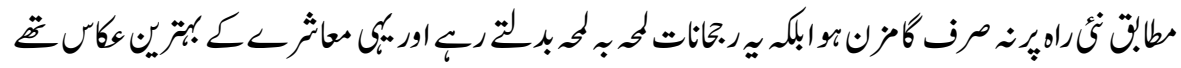

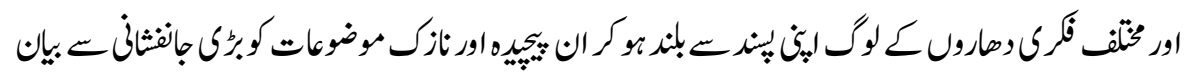

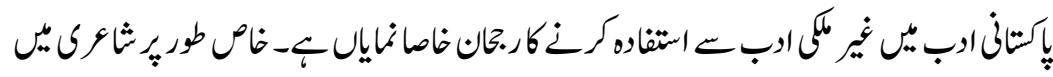

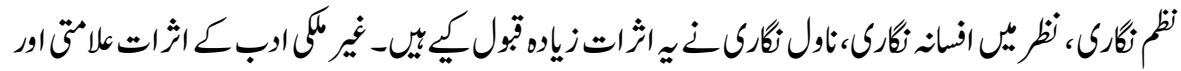

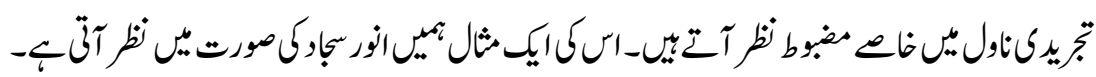

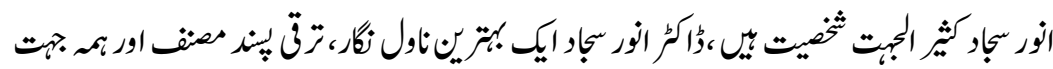

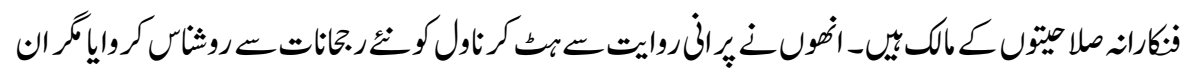

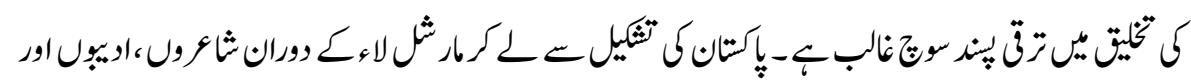

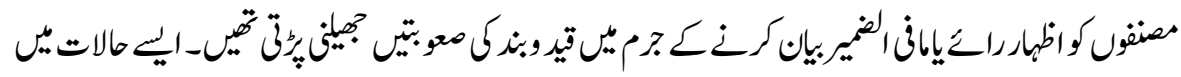

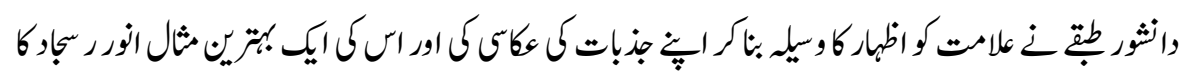

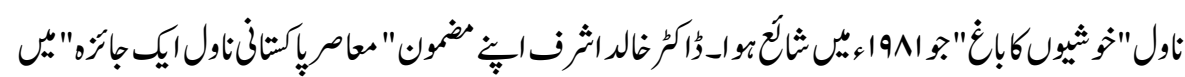
كلئين:

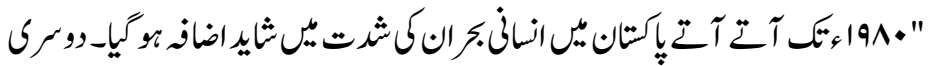

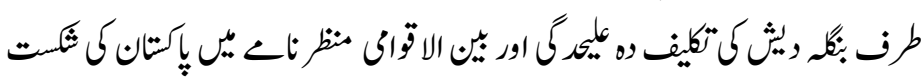

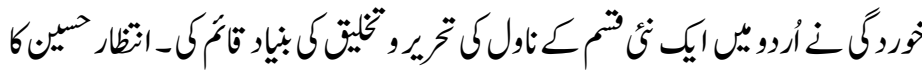




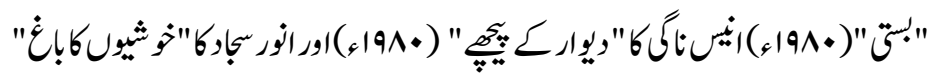
(19N1)

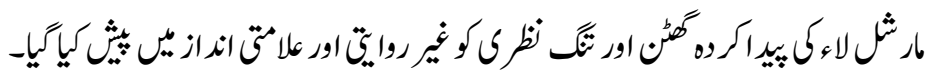

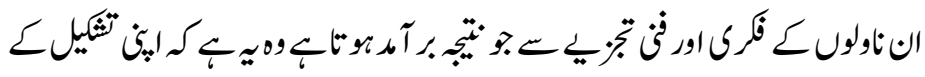

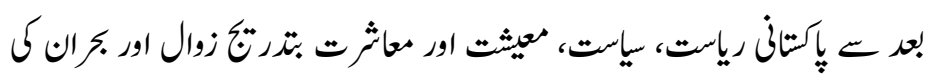

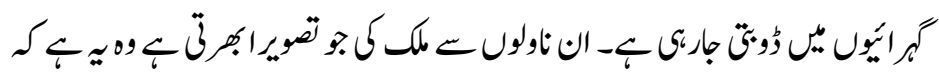

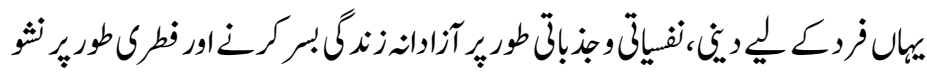

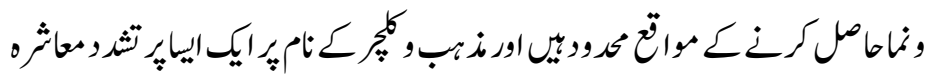

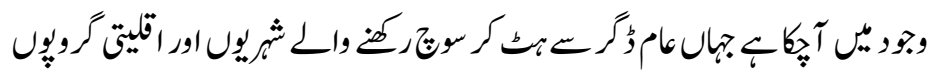

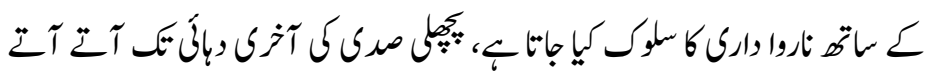

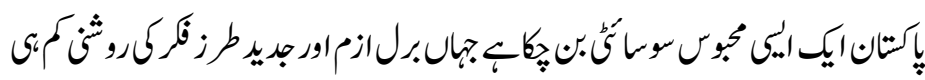
(1)"

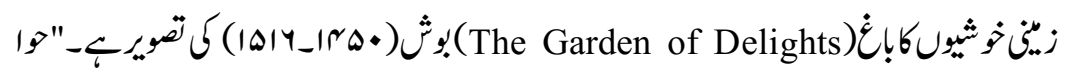

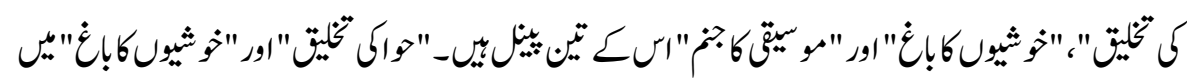

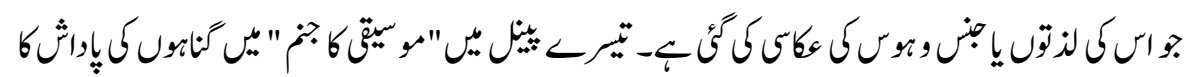
كبرتناكساجرابع-

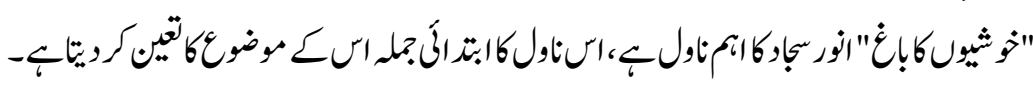

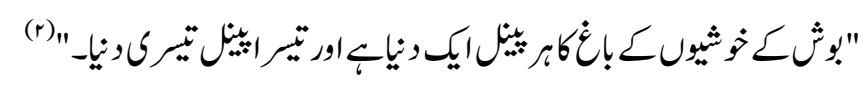

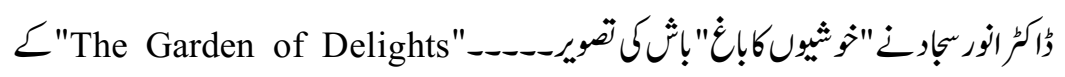

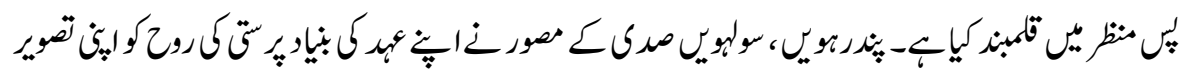

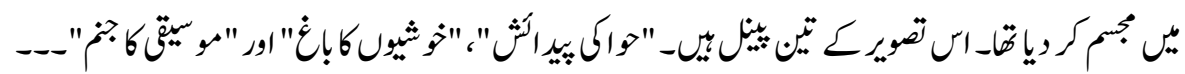

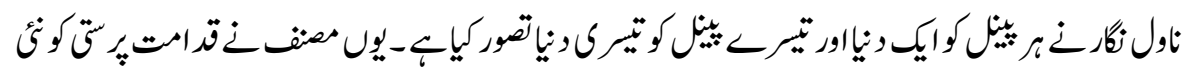

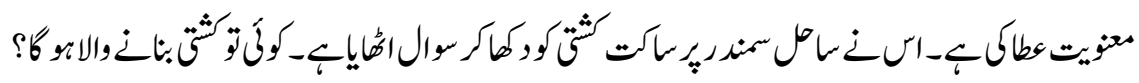




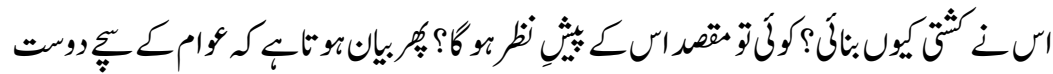

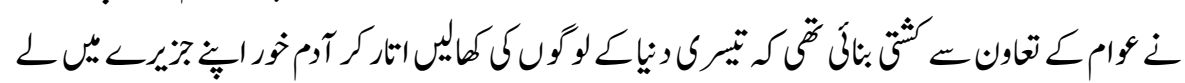

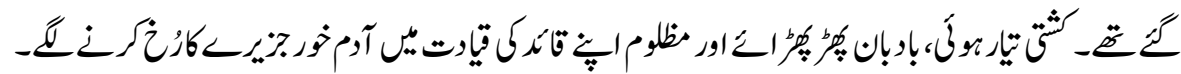

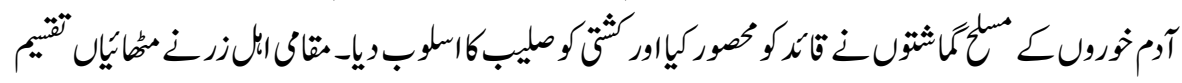

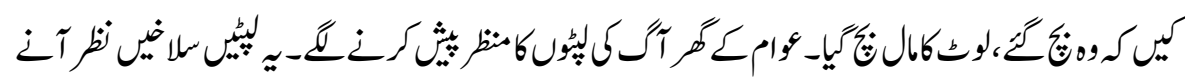

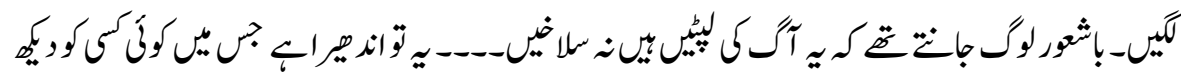

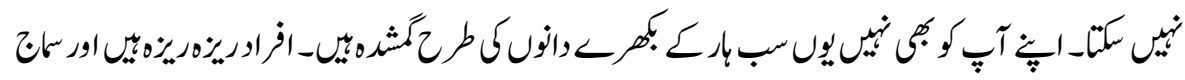
بـ شعورليورُ-

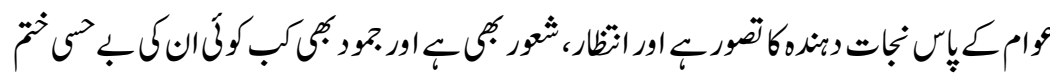

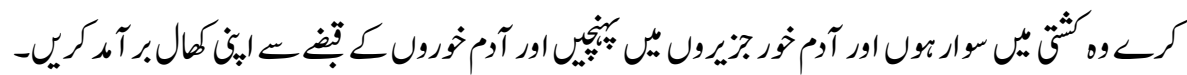

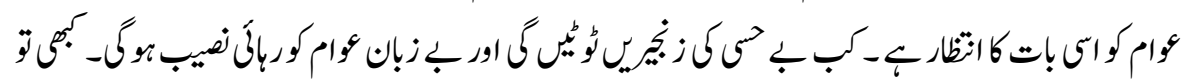

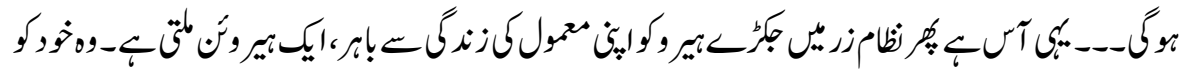

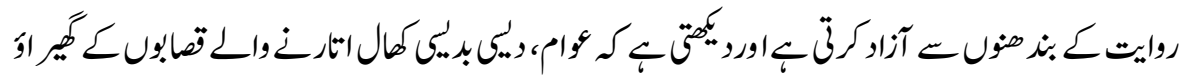

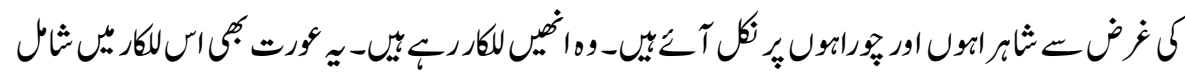

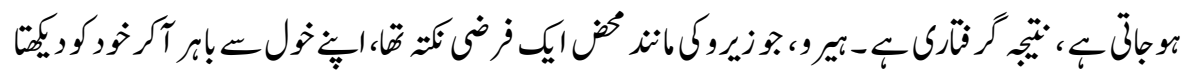

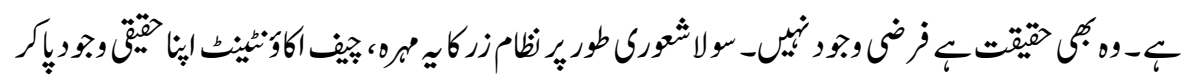

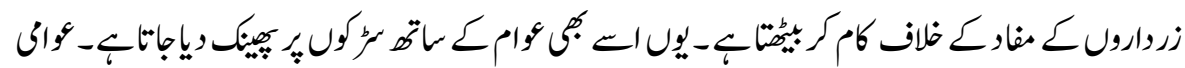

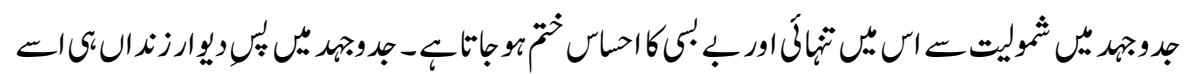

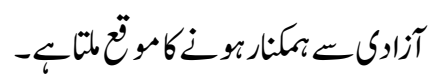

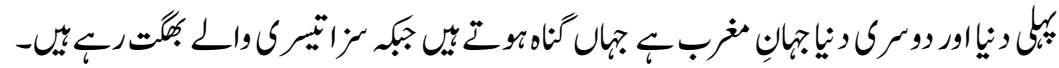

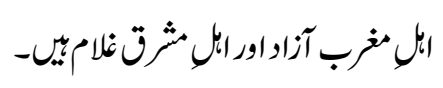

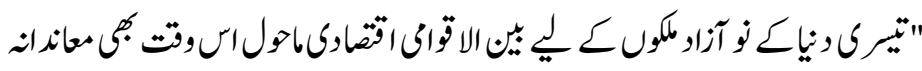

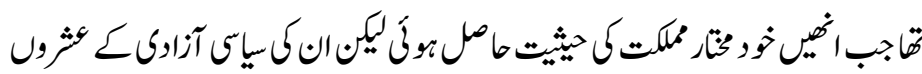




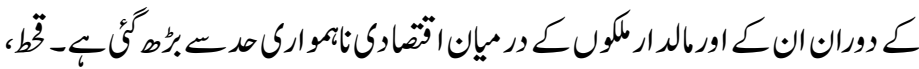

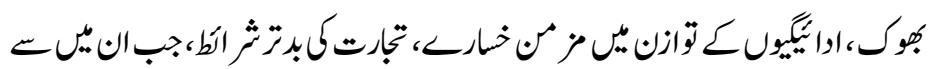

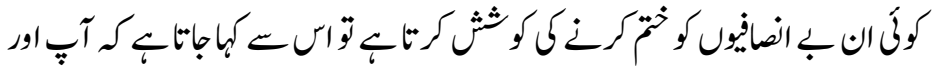

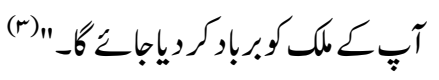

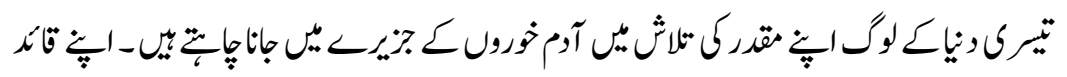

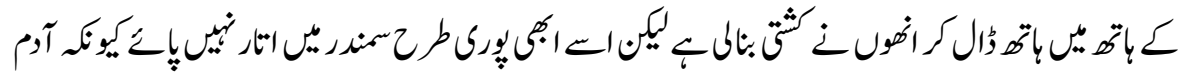

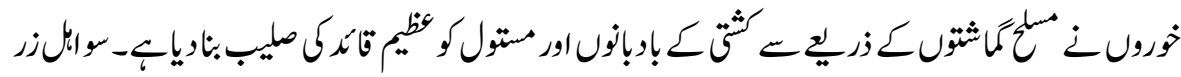

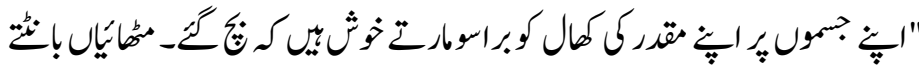

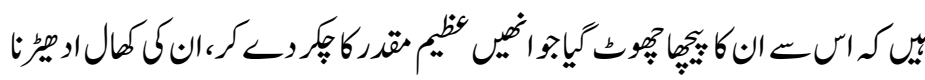

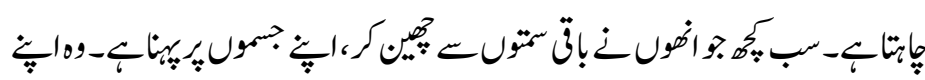

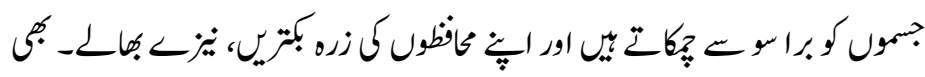

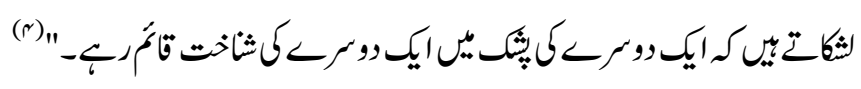

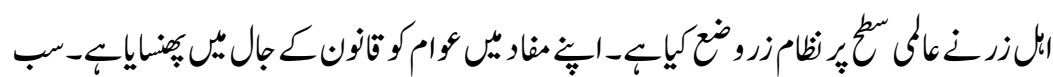

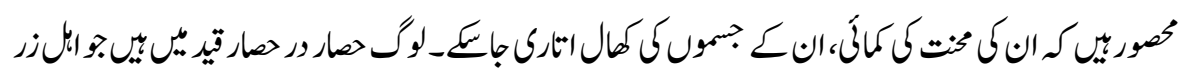

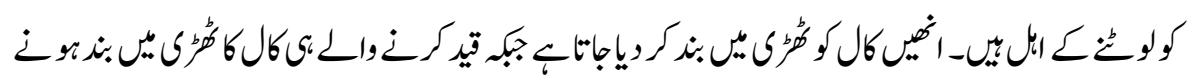

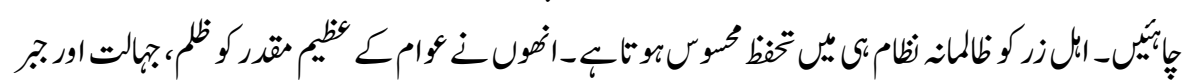

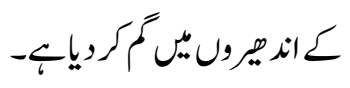

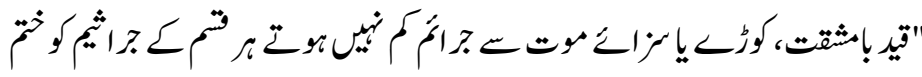

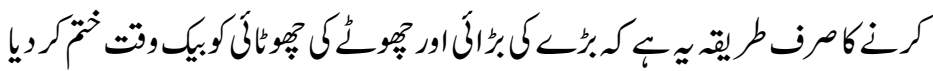

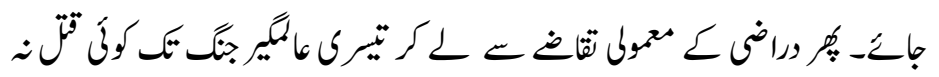

$(\Delta) "-b r$ 


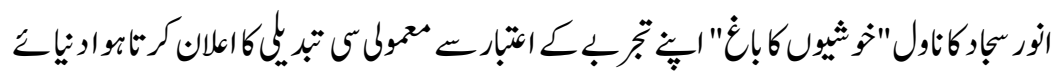

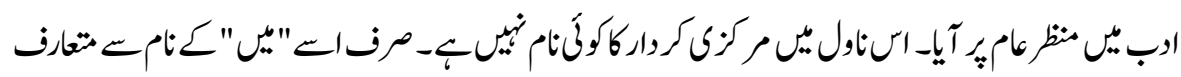

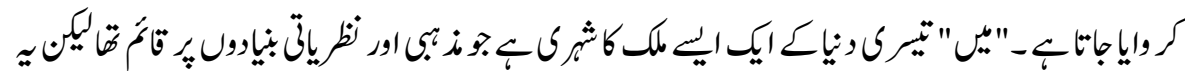

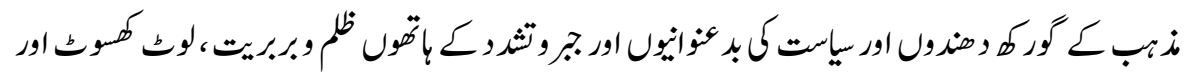

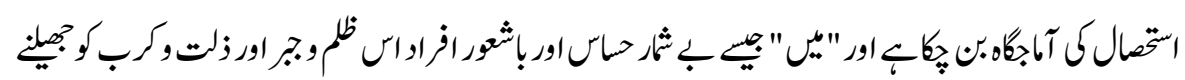

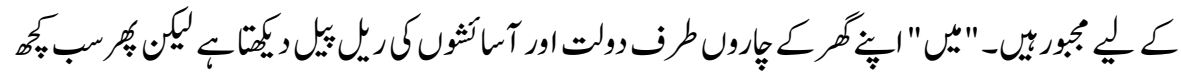

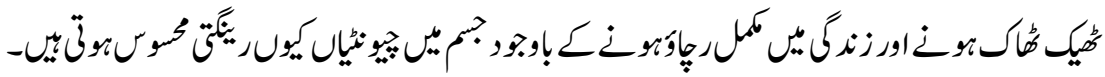

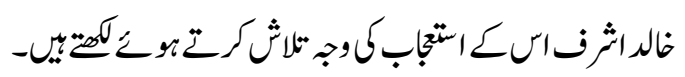

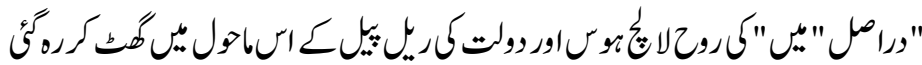

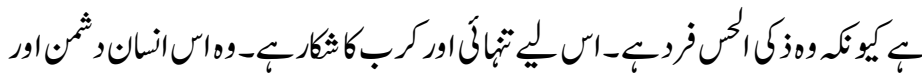

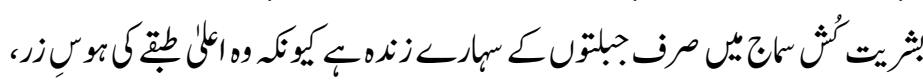

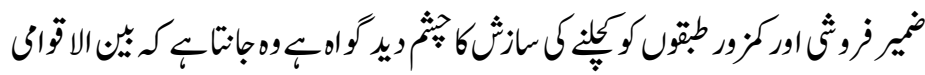

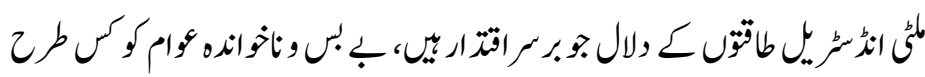

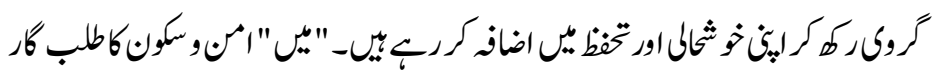

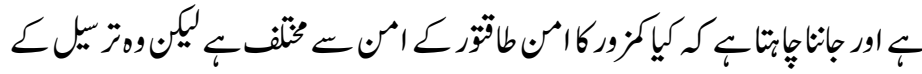

$$
\text { (4)"الميكة }
$$

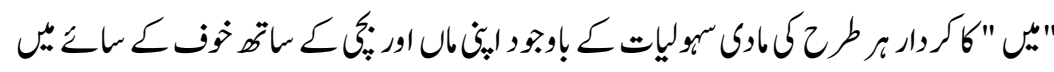

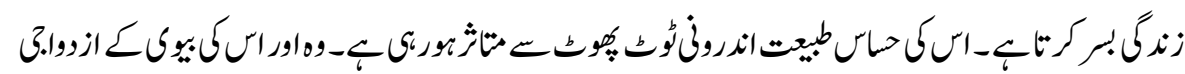

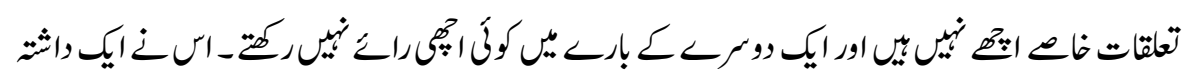

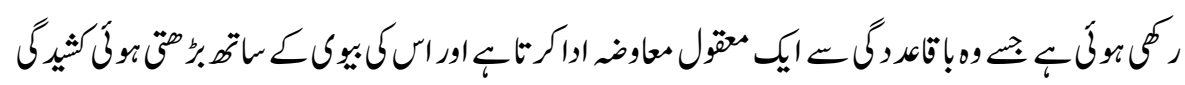

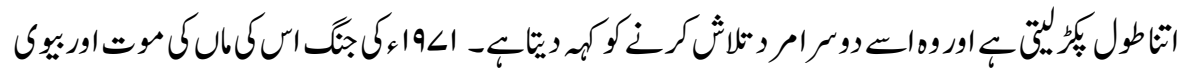

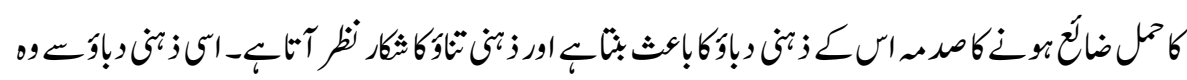

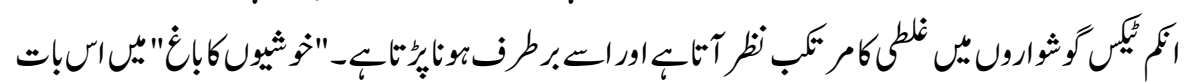




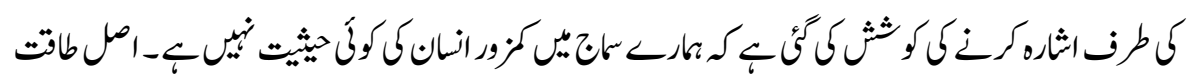

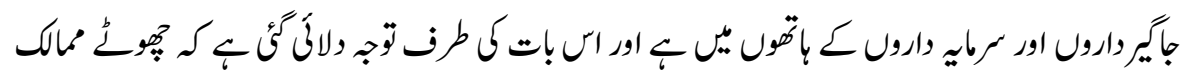

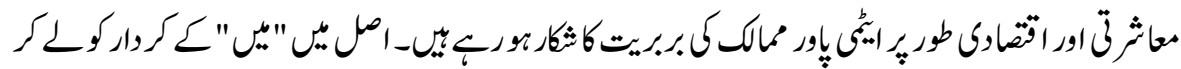

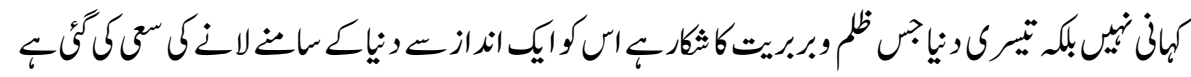

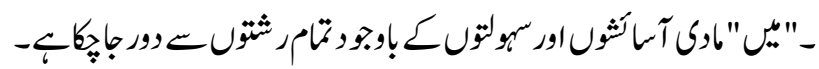

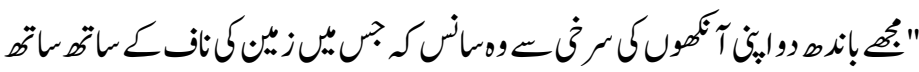

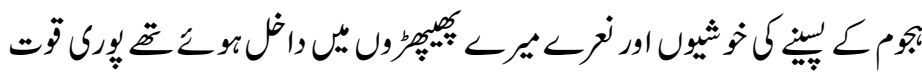

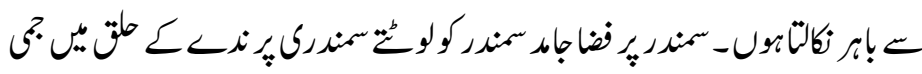

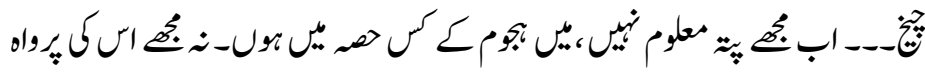

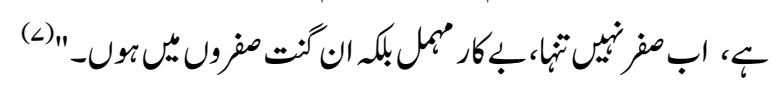

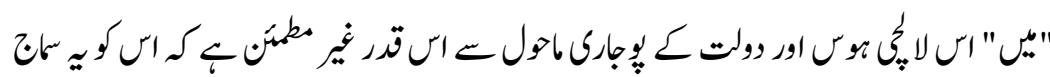

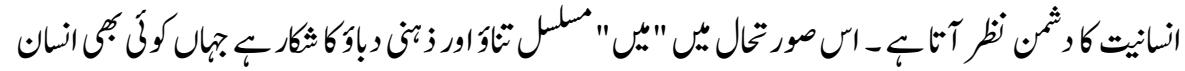

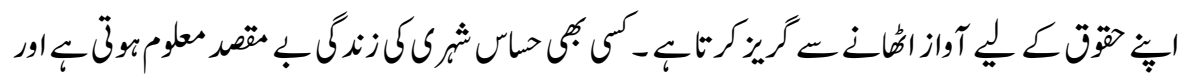

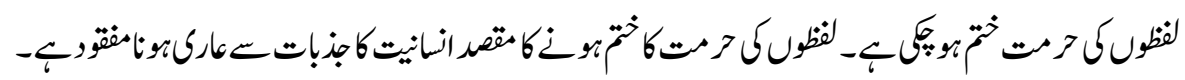

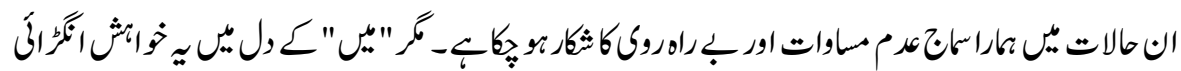

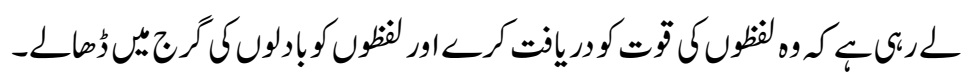

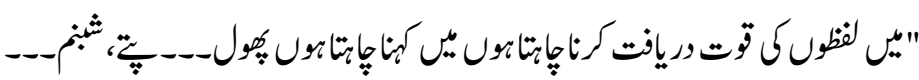

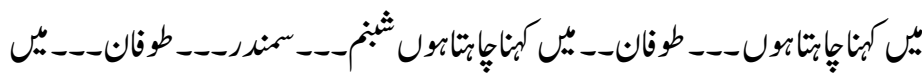

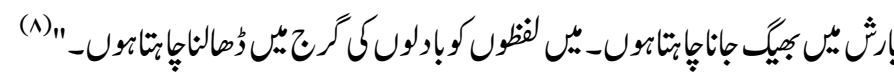

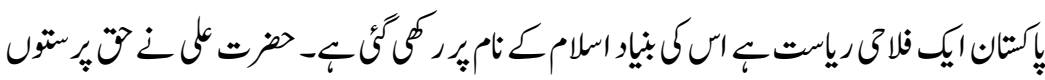

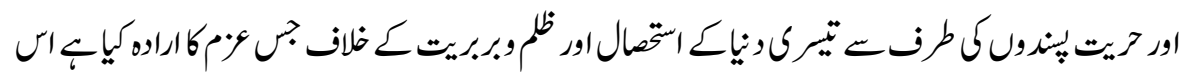

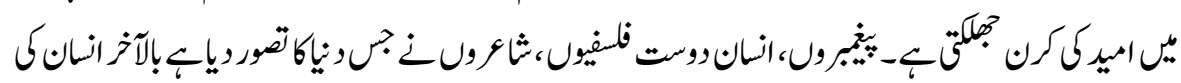

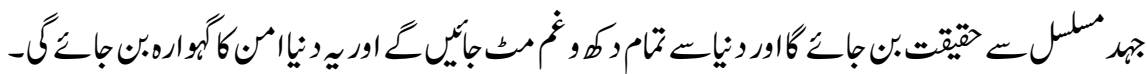




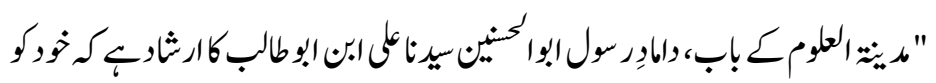

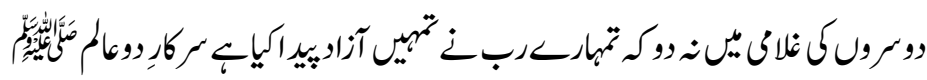

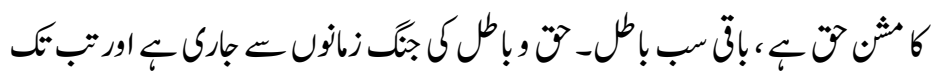

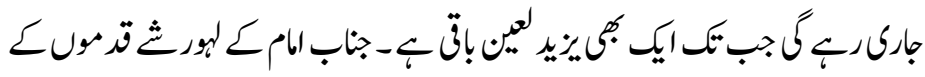

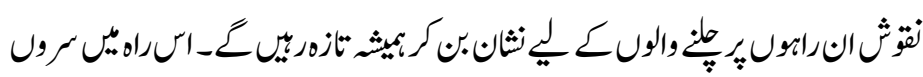

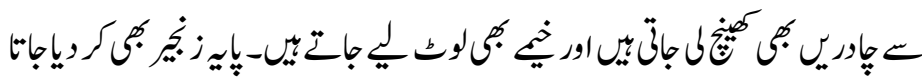

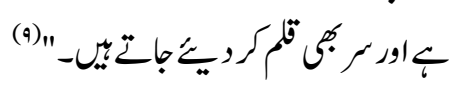

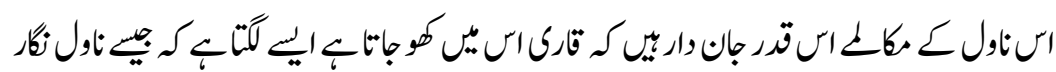

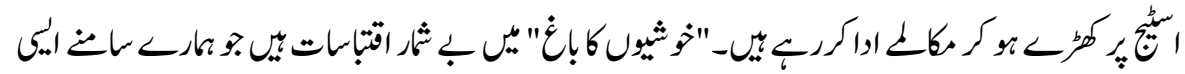

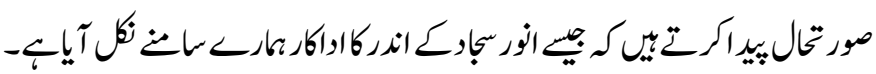

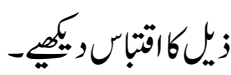

$$
\begin{aligned}
& \text { "توبكال }
\end{aligned}
$$

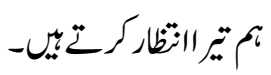

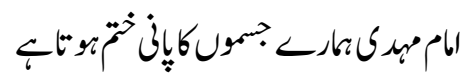

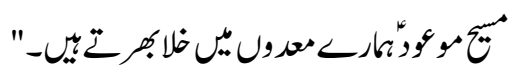

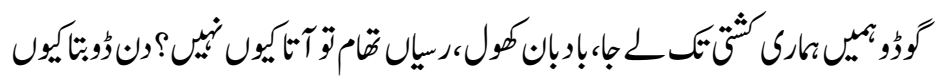

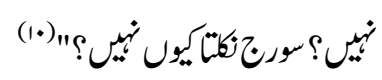

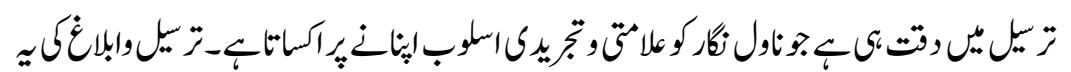

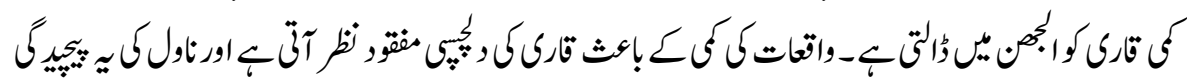

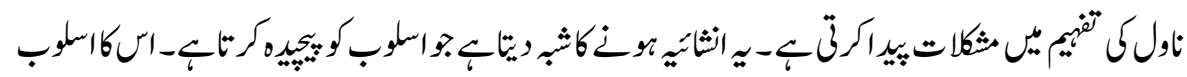

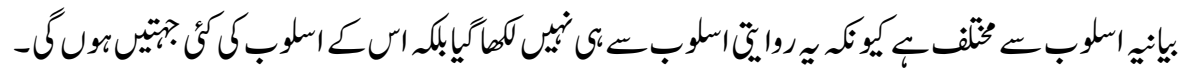

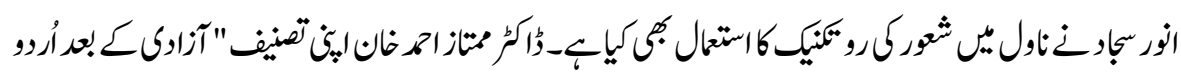

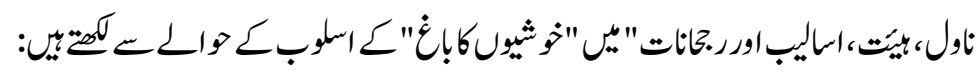




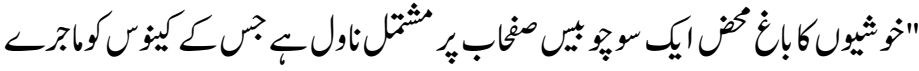

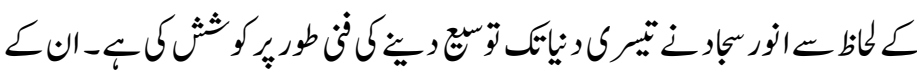

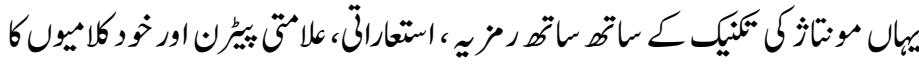

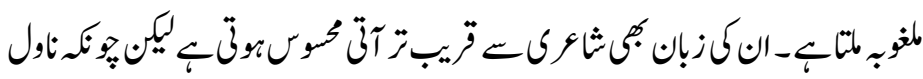

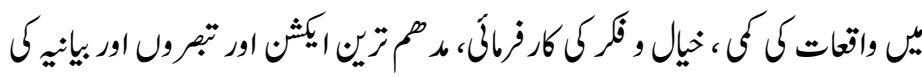

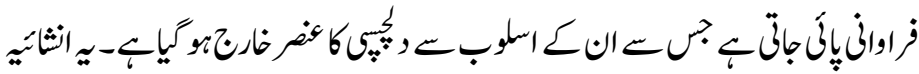

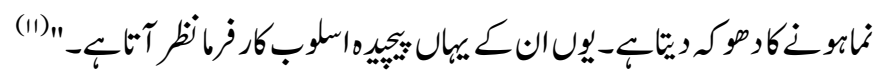

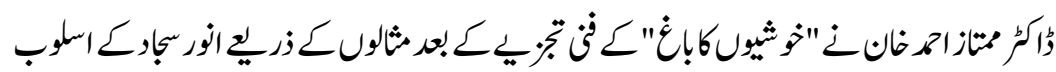

$$
\text { كوضاحتك }
$$

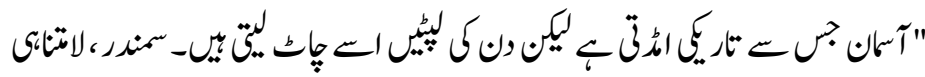

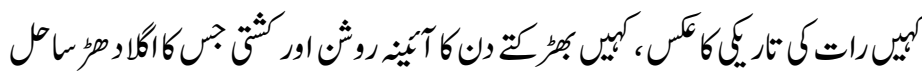

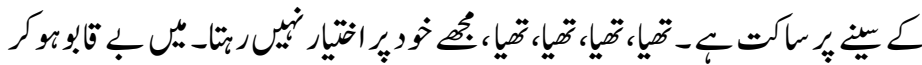

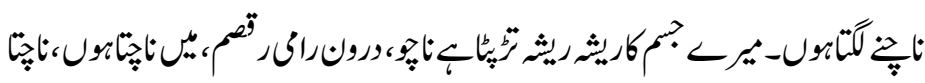

$$
\text { مون، تقال بي كثابوامر-" (ir) }
$$

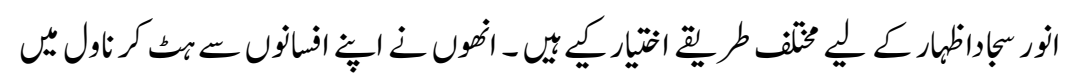

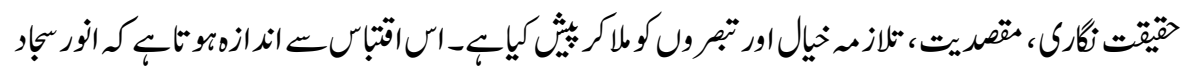

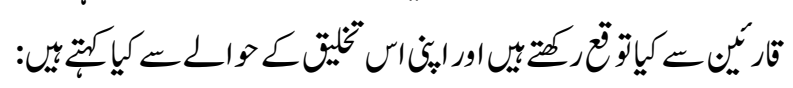

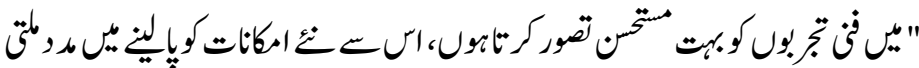

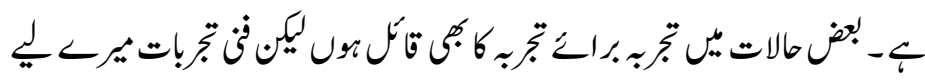

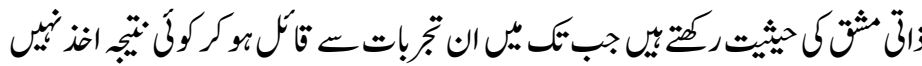

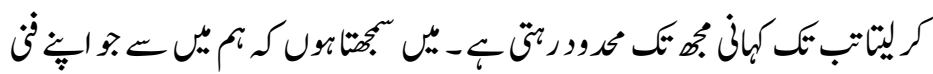

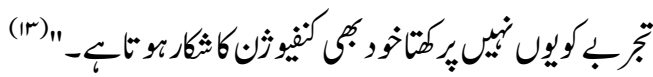




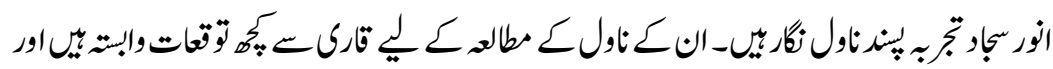

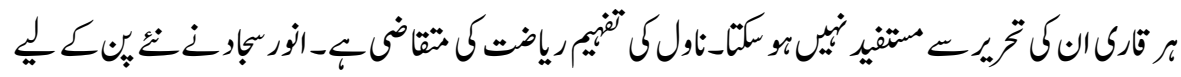

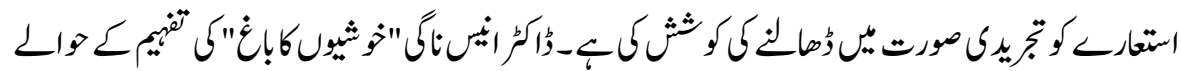

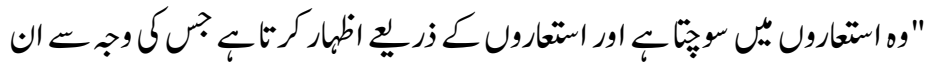

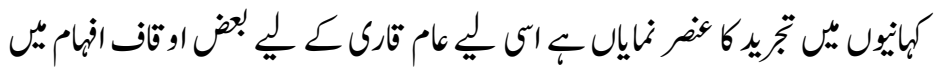

$$
\begin{aligned}
& \text { وتث ثيثن آنتب }
\end{aligned}
$$

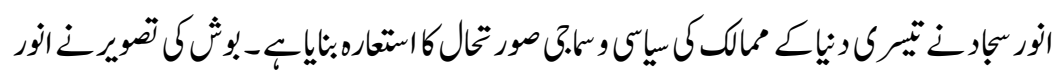

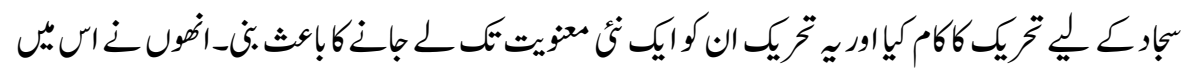

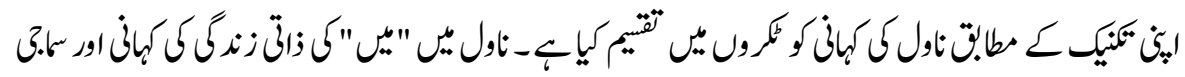

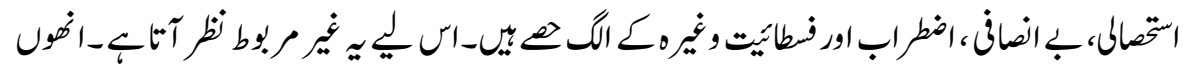

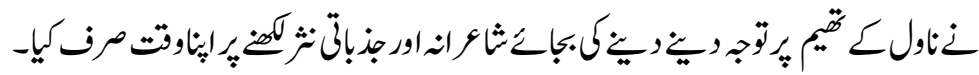

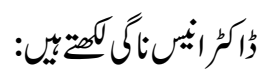

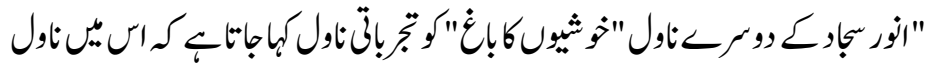

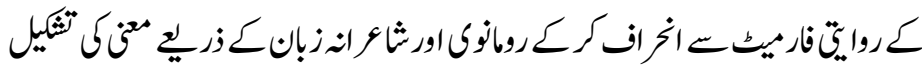

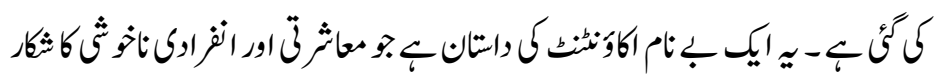

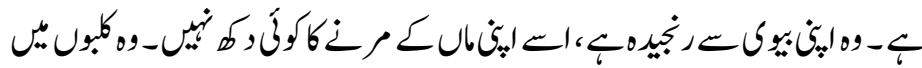

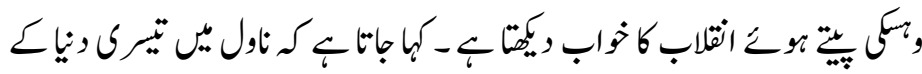

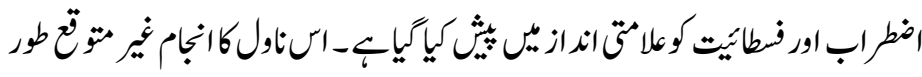

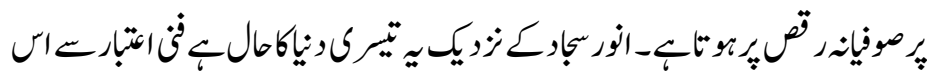

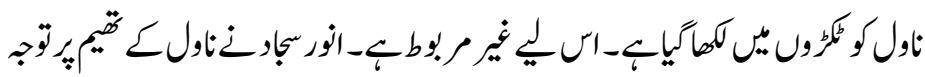

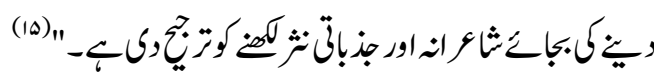




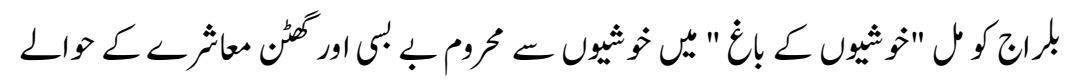

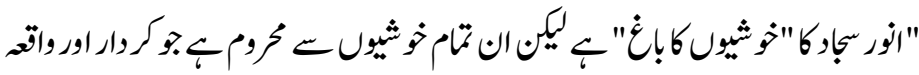

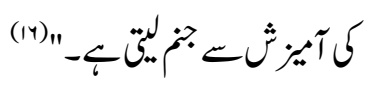

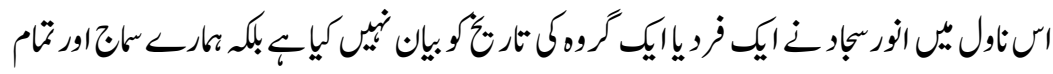

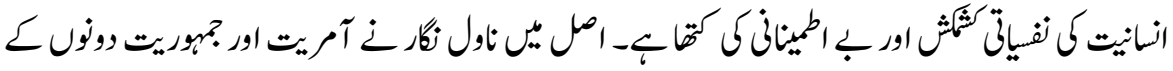

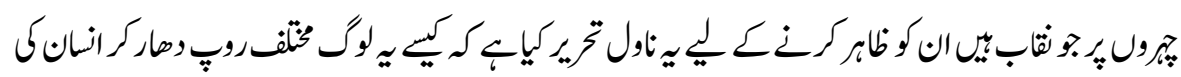

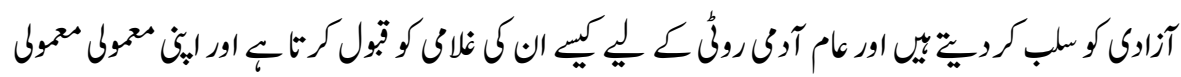

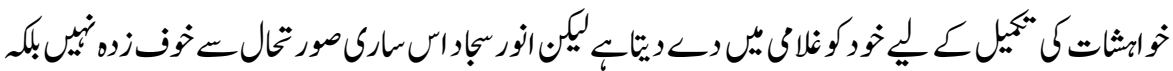

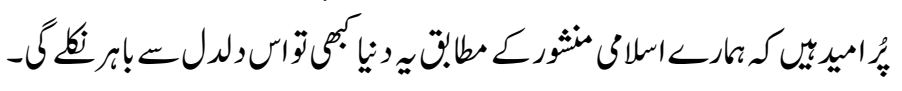

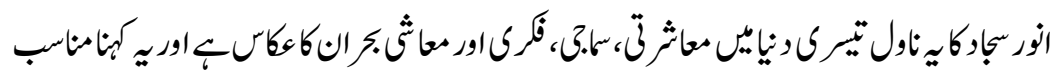

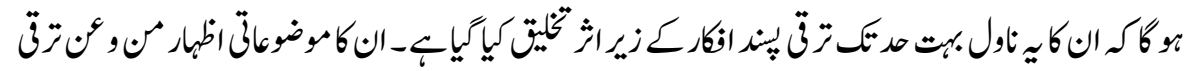

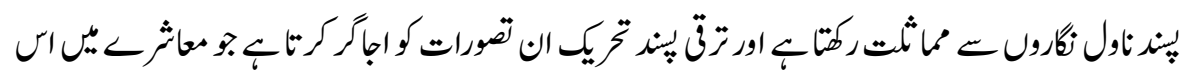

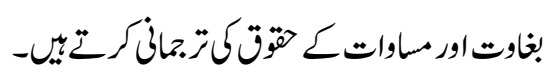
والدجات

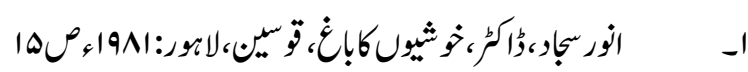

$$
\begin{aligned}
& \text { r } \\
& \text { r } \\
& \text { r }
\end{aligned}
$$

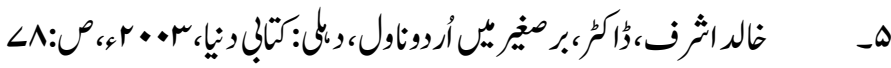

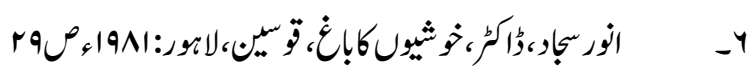

א-




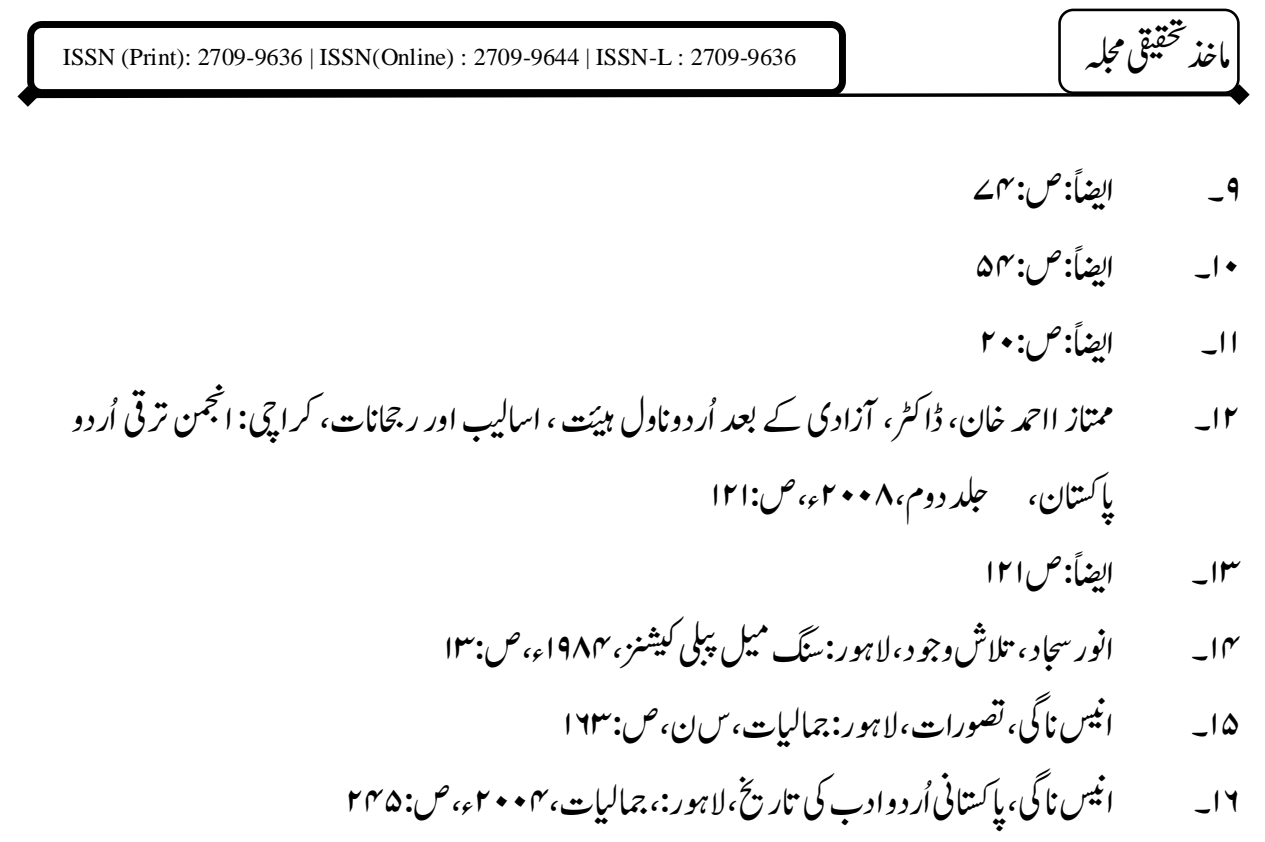

